\title{
Numerical Investigation on Faults Diagnosis for AC Induction Machine by Magnetic Flux Distribution
}

\author{
Linfeng $\mathrm{Li}^{1}$, Yating $\mathrm{Yu}^{1,2 *}$, Qin Hong ${ }^{1}$ and Zhenwei Wang ${ }^{3}$ \\ ${ }^{1}$ School of Mechnical and Electrical Engineering, University of Electronic Science and \\ Technology of China, Chengdu, 611731, China \\ ${ }^{2}$ Institute of Electronic and Information Engineering of UESTC in Guangdong, \\ 523808, Dongguan, China \\ ${ }^{3}$ School of Aeronautics and Astronautics, University of Electronic Science and \\ Technology of China, Chengdu, 611731, China
}

\begin{abstract}
AC induction machines are widely used in electric servo drive, information processing, transportation and other fields. However, the unexpected faults cause the serious threat for the normal operation and operator's safety. Therefore, timely faults diagnosis is an effective way to ensure the $\mathrm{AC}$ induction machines to work in health condition. In AC induction machines, magnetic field is the basis of energy conversion of motor, and the faults have the directly influence on the electromagnetic field distribution. In this paper, 2D numerical model of the $\mathrm{AC}$ squirrel-cage asynchronous induction machine is built by using COMSOL Multiphysics according to finite element method; Then, the magnetic flux distribution of $\mathrm{AC}$ induction motor with three different faults which commonly occurs in engineering are simulated. Base on the numerical simulation, the influence of the different faults on the magnetic distribution is discussed in detail. The investigation is beneficial to find a nondestructive fault diagnosis approach to the induction machine.
\end{abstract}

Keywords. AC induction machine, simulating calculation, magnetic flux distribution, faults diagnosis

\section{Introduction}

Induction machines play an important role in commercial manufacture. It is used in motor drive systems from few watts to several megawatts [1]. To ensure the reliable operation and long lifetime of machines, condition monitoring technologies have been developed to detect the occurred faults and predict impending failures. For the faults diagnosis, L.Siliang proposed a novel fast and online order analysis method, which composed of two algorithms to realize online diagnosis [2]. Rotor eccentricity can be diagnosed by extracting the amplitudes of stator current [3]. By improved motor current signal model can makes the monitoring of rotor bar fault more accurate [4]. The method

\footnotetext{
*Corresponding author:86-13678139939,E-mail address:yuyating-uestc@hotmail.com
} 
of Complete Ensemble Empirical Mode utilize spectrum analysis technology can detect induction motor faults in steady-state operation [5].

Eddy current exists in motor and directly influence magnetic flux density (MFD) distribution. Therefore, the faults can influence the magnetic distribution. To investigate the influence of the rotor eccentricity, rotor bar breakage and shaft crack on the MFD distribution, the FE model is set up, and the relationship of the faults and the MFD are studied in detail. Consequently, the approach to fault diagnosis are proposed.

\section{FE modelling}

$\mathrm{AC}$ induction machine structure is shown in Figure 1. The electrical and geometric parameters of the machine are listed in Table 1. The materials and their parameters of motor parts are listed in Table 2. The revolving speed of the magnetic field is $1500 \mathrm{rpm}$ through calculating. And setting the speed of the rotor as $1485 \mathrm{rpm}$ in simulation.

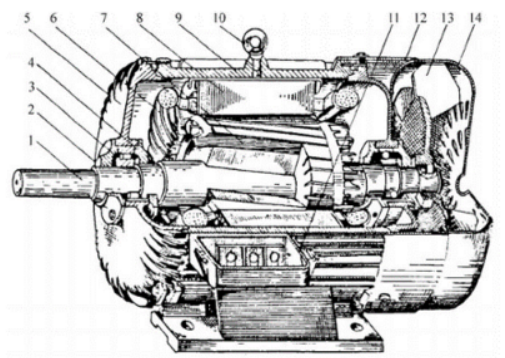

Figure 1. The structure of the AC induction machine. 1-shaft, 2, 4-bearing cap; 3-bearing; 5,12-frame; 6stator winding; 7-rotor; 8- stator core; 9-base; 10-ring; 11-outlet box; 13-electric fan; 14-fan housing

Table 1. The electrical parameters and geometric parameters of the machine

\begin{tabular}{|c|c|c|c|c|c|}
\hline Rated power & $3 \mathrm{KW}$ & Armature slot number & 24 & Height of air gap & $4 \mathrm{~mm}$ \\
\hline Rated voltage & $380 \mathrm{~V}$ & Pole number & 4 & Outer Diameter of stator & $130 \mathrm{~mm}$ \\
\hline Rated current & $6.8 \mathrm{~A}$ & Phase number & 3 & Inter Diameter of stator & $96 \mathrm{~mm}$ \\
\hline Height of core & $120 \mathrm{~mm}$ & Stator slot number & 24 & Outer Diameter of rotor & $88 \mathrm{~mm}$ \\
\hline Shaft diameter & $24 \mathrm{~mm}$ & Excitation frequency $(\mathrm{Hz})$ & 50 & & \\
\hline
\end{tabular}

Table 2. The material and material parameters of the key components in machine

\begin{tabular}{|c|c|c|c|c|c|}
\hline Components & Core & $\begin{array}{c}\text { Stator } \\
\text { wingding }\end{array}$ & $\begin{array}{c}\text { Rotor } \\
\text { winding }\end{array}$ & $\begin{array}{c}\text { Air } \\
\text { gap }\end{array}$ & Shaft \\
\hline material & Soft steel & Copper & Copper & air & Steel \\
\hline Ralative magnetic permeability & H-B curve & 1 & 1 & 1 & 1 \\
\hline Relative Permittivity & 1 & 1 & 1 & 1 & 1 \\
\hline Electrical conductivity $(\mathrm{MS} / \mathrm{m})$ & 11.20 & 59.98 & 59.98 & 0 & 4.03 \\
\hline Area of cross section $\left(\mathrm{mm}^{2}\right)$ & $/$ & 12.57 & 21.36 & $/$ & $/$ \\
\hline Turns number & $/$ & 30 & 1 & $/$ & $/$ \\
\hline
\end{tabular}

To simulate the relative motion of the stator and rotor, two independent coordinate systems are set in FE model. One is the stator coordinate system which is fixed on stator, the other is the rotor coordinate system which is fixed on rotor. In simulation, the former is moving and latter is static. The CAD model, mesh model and FE model with the boundary conditions are shown in Figure 2.

According to the FE model in Figure 2, we can obtain the magnetic flux density distribution of the AC machine, and shown in Figure 3. As that can been seen in Figure 
3 , the most of the magnetic flux form the closed electromagnetic loop by stator core-air gap-rotor core. A few magnetic flux surrounded in the vicinity of the stator core is leakage. Based on the FEM model, the influence of the rotor eccentricity, the rotor bar/ring breakage and shaft crack on the magnetic flux density are investigated.

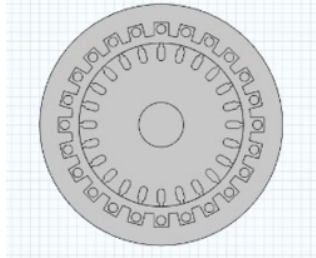

(a)

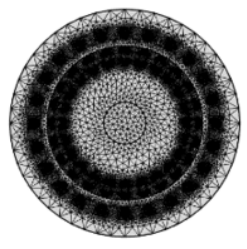

(b)

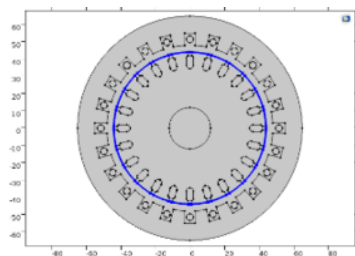

(c)

Figure 2. FE model. (a) CAD model (b) mesh model (c) sharing boundary

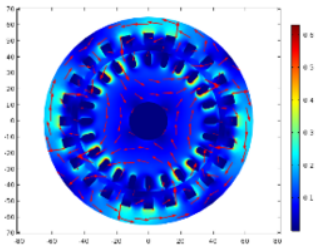

(a)

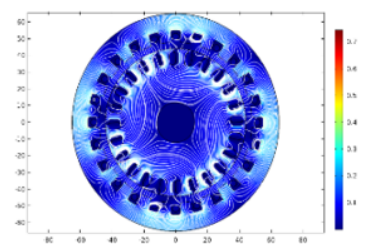

(b)

Figure 3. MFD distribution of machine (a) vectorgraph; (b) isogram

\section{Study on the influence of different faults on magnetic field distribution of motor}

Induction machines typically operate at harsh environment which leads to approximately $6 \%$ failure rate each year [6]. The bear failure rate is $37 \%$, rotor eccentricity is $12 \%$, shaft is $5 \%-10 \%$ [7]. Among these failure machines, several surveys have investigated and illustrated the detailed failure types and rates [8]. The common failures of induction machines include stator winding faults, bearing faults, rotor bar/ring faults and shaft failures [9]. Therefore, three typical faults: Rotor eccentricity, Rotor bars breakage and crack in shaft are considered in this paper.

\subsection{Rotor eccentricity}

Eccentricity faults may occur in the squirrel-cage asynchronous induction machine's air gap between the outer side of the rotor and the inner side of the stator due to manufacturing process or operational wear [10]. There are two kinds of air gap eccentric faults: static eccentric and dynamic eccentric [11].

In this paper, the distribution of magnetic field of the $\mathrm{AC}$ induction machine (ACIM) with static eccentricity is studied. When no static eccentricity in rotor, the center point of rotor is $(0.00 \mathrm{~mm}, 0.00 \mathrm{~mm})$. In order to investigate the influence of the rotor eccentricity on the magnetic field of ACIM, we set the center point of rotor is $(0.50 \mathrm{~mm}$, $0.50 \mathrm{~mm}),(1.00 \mathrm{~mm}, 1.00 \mathrm{~mm})$ and $(1.50 \mathrm{~mm}, 1.50 \mathrm{~mm})$, respectively. The distribution of the magnetic field of the ACIM under the different eccentricity are shown in Figure 4.

As the eccentricity distance of the rotor increases, the distribution of the magnetic field lines of the motor become denser when the air gap become narrow. In the contrary, the distribution of magnetic field lines becomes sparser where the air gap become wide. 


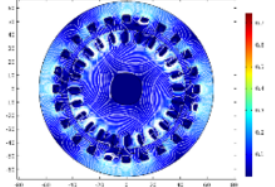

(a)

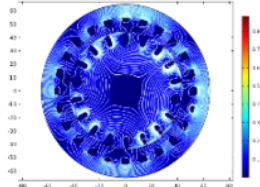

(b)

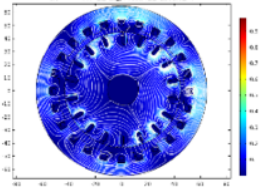

(c)

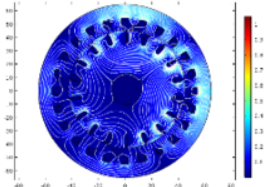

(d)

Figure 4. Magnetic field line distribution of ACIM when different static eccentricity in rotor. (a)rotor center $(0.00,0.00)$; (b)rotor center(0.50,0.50); (c)rotor center $(1.00,1.00)$; (d)rotor center $(1.50,1.50)$

In order to analyze quantitatively, six reference points shown in Figure 5 (a) are taken to compare the MFD values. The variation tendency of MFD is shown in Figure 5 (b). For the points $\boldsymbol{a}, \boldsymbol{c}$ and $\boldsymbol{e}$, the MFD increase with the increase of the eccentricity distance of the rotor. For the three points $\boldsymbol{b}, \boldsymbol{d}$ and $\boldsymbol{f}$, the MFD decrease with the increase of the eccentricity distance. The reason is that the rotor is closer the points $\boldsymbol{a}, \boldsymbol{c}$ and $\boldsymbol{e}$ for the increasing distance of the rotor, while it is farer the points $\boldsymbol{b}, \boldsymbol{d}$ and $\boldsymbol{f}$.

For making comparison, the difference of the MFD between each set of symmetrical points are grouped. Group 1 includes point $\boldsymbol{a}$ and $\boldsymbol{b}$, group 2 includes point $\boldsymbol{c}$ and $\boldsymbol{d}$, group 3 includes point $\boldsymbol{e}$ and $\boldsymbol{f}$, as well as group 4 includes point $\boldsymbol{h}$ and $\boldsymbol{i}$. The variation curve of MFD difference of each symmetrical point with the distance of rotor eccentricity is shown in Figure 5 (c).

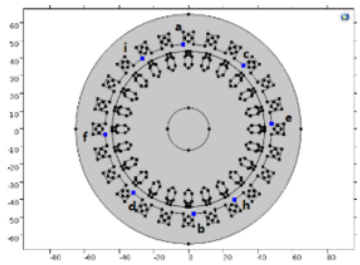

(a)

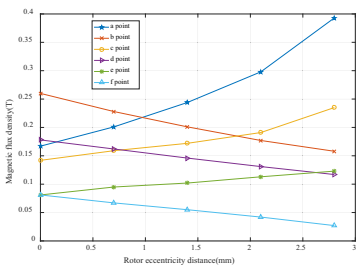

(b)

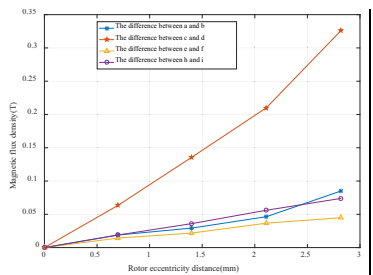

(c)

Figure 5.(a) Values points of rotor eccentricity motor; (b) Variation curve of MFD with eccentricity distance at value points; (c) The difference of the MFD of the four groups with the rotor eccentricity

The difference of MFD at the symmetric point of the motor is almost 0 when there is no eccentricity. While, it is linear changing with the increase of the eccentricity distance. Importantly, the difference between point $\boldsymbol{c}$ and $\boldsymbol{d}$ is most sensitive to the change of the motor eccentricity distance. Therefore, we can not only easily character the rotor eccentricity distance, but also confirm the direction of the rotor eccentricity by detecting the MFD difference in the symmetrical detection points.

\subsection{Rotor bars breakage}

This section analyzed the electromagnetic field distribution of the ACIM when 4 and 8 rotor bars are broken. The locations of the broken bars are shown in Figure 6 .

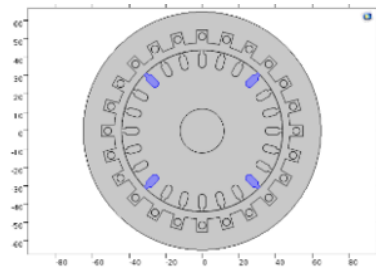

(a)

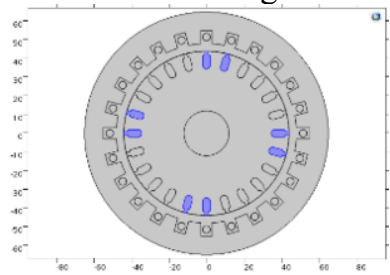

(b)

Figure 6. The layout of the broken rotor bars (a) 4 rotor bars are broken; (b) 8 rotor bars are broken

For 4 broken rotor bars, two points near the broken rotor bar are marked as $\boldsymbol{A}$ and $\boldsymbol{B}$, and marked $\boldsymbol{C}$ and $\boldsymbol{D}$ near the normal rotor bar. For 8 broken rotor bars, three points near 
the broken bars and marked them as $\boldsymbol{E}, \boldsymbol{F}$ and $\boldsymbol{G}$. Meanwhile, another three points are taken near the normal rotor bars which is named as $\boldsymbol{H}, \boldsymbol{I}$ and $\boldsymbol{J}$. The layout of the detection points is shown in Figure 7. The MFD values of each point are listed in Table 3.

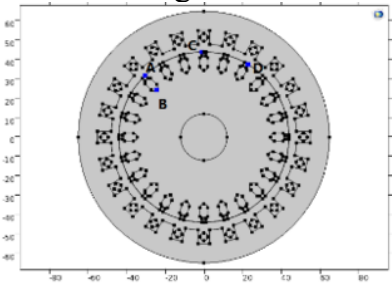

(a)

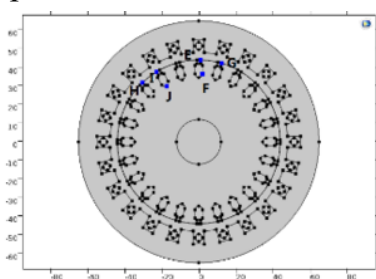

(b)

Figure 7. Roken rotor bar points (a)4 rotor bars are broken; (b) 8 rotor bars are broken

Table 3. MFD value at different points: (Gs)

\begin{tabular}{|c|c|c|c|c|c|c|c|c|c|c|}
\hline \multirow{2}{*}{ Status } & \multicolumn{3}{|c|}{ P rotor bars are broken } & \multicolumn{5}{|c|}{8 rotor bars are broken } \\
\cline { 2 - 12 } & $\mathrm{A}$ & $\mathrm{B}$ & $\mathrm{C}$ & $\mathrm{D}$ & $\mathrm{E}$ & $\mathrm{F}$ & $\mathrm{G}$ & $\mathrm{H}$ & $\mathrm{I}$ & $\mathrm{J}$ \\
\hline normal & 885 & 2882 & 279 & 1342 & 924 & 1297 & 855 & 885 & 1677 & 2868 \\
\hline fault & 1041 & 3002 & 273 & 1340 & 1112 & 1431 & 1018 & 885 & 1649 & 2816 \\
\hline
\end{tabular}

From Table 3, we can see that the MFD of the points near the broken bars is obviously higher than the normal condition, while the MFD near the normal bars have little effect by the broken bars. Therefore, we can judge whether the bar breaks or not by detecting the MFD.

\subsection{Crack in shaft}

For considering the influence of the V shape fatigue crack in the shaft on the MFD. The crack depth along the radial direction is $5.00 \mathrm{~mm}$, and the angle of crack of $6^{\circ}, 8^{\circ}$ and $10^{\circ}$ are considered. The magnetic field line distributions are shown in Figure 8.

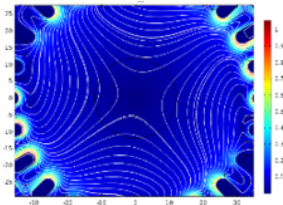

(a)

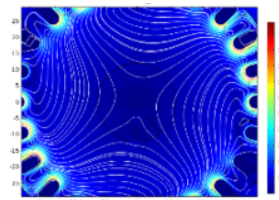

(b)

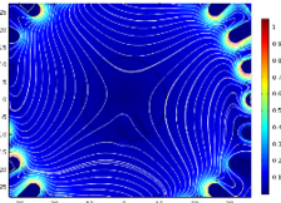

(c)

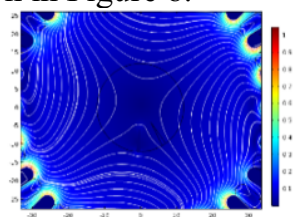

(d)

Figure 8. MFD lines with different crack degrees. (a) crack free; (b) spread angle is $6^{\circ}$;

(c) spread angle is $8^{\circ} ;(\mathrm{d})$ spread angle is $10^{\circ}$

Two reference points are taken to analysis the MFD of different crack degrees. The infulece of the crack in the shaft on the MFD are shown in Figure 9 (a).

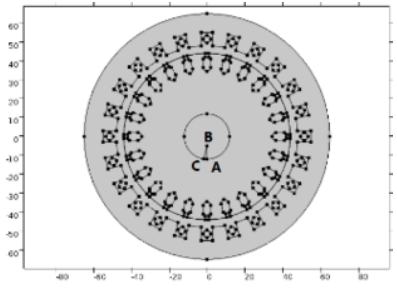

(a)

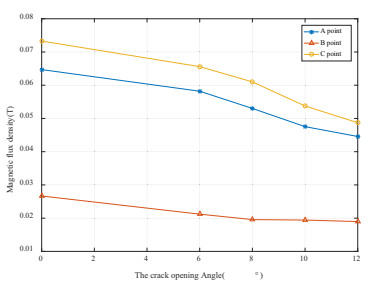

(b)

Figure 9. The infulece of the crack in the shaft on the MFD. (a)the layout of the detection points; (b)the curves of the crfack angle and the magetic flux desnity

Cracks makes the MFD at all detection points decrease compared with the normal condition and the increasing crack angle makes the monotone decreasing of the MFD. However, the influences of the crack on the MFD at point $\mathrm{A}$ and point $\mathrm{C}$ are greatly 
higher than point B. Therefore, we can determine the crack position and crack angle by compare the MFD with that under normal operation of the motor.

\section{Conclusion}

The variation of MFD of motor under different faults is obtained by numerical simulating, and analyzed in detail. The rotor eccentricity distance as well as the direction of the rotor eccentricity can be diagnosed by detecting the magnitude of the flux density difference in the symmetrical detection points in air gap of the ACIM; the broken bars position can be diagnosed by comparing the MFD distribution near the bars under the fault condition with that under the normal condition; the crack position and crack angle in shaft can be determined by comparing the MFD of the points on the surface of the rotation shaft with that under normal operation of the motor. Therefore, numerical simulations indicate that MFD can be applied to diagnose the three commonly appeared faults in ACIM. In future, a validation by experimental study to the numerical simulation results will be considered.

\section{Acknowledgements}

This work is supported by the National Nature Science Foundation of Guangdong Province [grant number is 2018A030313893], the Fundamental Research Funds for the Central Universities [grant number is ZYGX2018J067] and the National Nature Science Foundation of China [grant number is 51675087].

\section{References}

[1] W. Cao, K. J. Bradley, Assessing the impacts of rewind and repeated rewinds on induction motors is an opportunity for Re-designing the machine being wasted. IEEE Transactions on Industry Applications 42 (2006), 958-964.

[2] L. Siliang, H. Qingbo, Zh Jiwen, Bearing fault diagnosis of a permanent magnet synchronous motor via a fast and online order analysis method in an embedded system. Mechanical. Systems. and Signal Processing. 113(2018), 36-49.

[3] B.M. Ebrahimi, J. Faiz, et,al. Static-dynamic-and mixed-eccentricity fault diagnoses in permanent magnet synchronous motors, IEEE Transactions on Industry Electronics, 56(2009), 4727-4739.

[4] F. Gu, T. Wang, A.Alwodai, X.Tian, Y. Shao, A. Ball. A new method of accurate broken rotor bar diagnosis based on modulation signal bispectrum analysis of motor current signals. Mechanical. Systems. and Signal Processing 50(2015), 400-414.

[5] P.A. Delgado-Arredondo, D. Morinigo-Sotelo, et al. Methodology for fault detection in induction motors via sound and vibration signals. Mechanical. Systems and Signal Processing 88(2017), 568-589.

[6] A.H. Bonnett, G.C. Soukup, Cause and analysis of stators and rotor failures in 3-phase squirrel-cage induction-motors, IEEE Transactions. on Industry Application 28(1992), 921-937.

[7] A.Sidique, G.S. Yadava, B. Singh. A review of stator fault monitoring techniques of induction motors. IEEE Transactions. Energy Conversion 20(2005), 106-114.

[8] O.V. Thorsen. A survey of faults on induction motors in offshore oil industry, petrochemical industry, gas terminals and oil refineries, IEEE Transactions on Industry Application 31(1994),1186-1196.

[9] Liu Z, Cao W, Huang P H, Non-invasive winding fault detection for induction machines based on stray flux magnetic sensors, IEEE Power and Energy Society General Meeting. JUL 17-21, 2016, Boston, MA.

[10] M. Blodt, P. Granjon, P. Raison, Models for bearing damage detection in induction motors using stator current monitoring. IEEE Transactions on Industrial Electronics, 55(2008), 1813-1822.

[11] Fenger, M, Lloyd, BA, Thomson, WT, Development of a tool to detect faults in induction motors via current signature analysis. 45th Annual Cement Industry Technical Conference, MAY 04-09, 2003, DALLAS, TX. 